\title{
As Origens dos Recentes Defaults da Economia Brasileira Efeitos da Economia Real ou Decorrentes de Transações Puramente Financeiras?
}

http://dx.doi.org/10.21527/2237-6453.2021.54.48-67

Recebido em: $7 / 5 / 2020$

Aceito em: 25/11/2020

Erika Burkowski ${ }^{1}$, Jiyoung Kim²

\begin{abstract}
RESUMO
$\mathrm{O}$ artigo busca compreender as origens das recentes quedas no produto da economia brasileira (defaults) observadas nos anos de 2009, 2015 e 2016, verificando se estão relacionadas à economia real ou a transações puramente financeiras, e busca, também, discutir os fatores relacionados às causas detectadas. Aplicou-se a análise de fluxo de fundos para a economia brasileira de 2004 a 2015, que permitiu observar que as transações financeiras espelharam as transações reais ao longo do período, exceto em 2008, mostrando que a causa do default de 2009 está relacionada a alterações nos portfólios financeiros e que os defaults de 2015 e 2016 estão fortemente relacionados a fatores da economia real. Alterações na posição estrutural dos setores institucionais evidenciaram a perda do "espaço de política" do governo e maior participação das empresas financeiras no fluxo de fundos com o incentivo do Banco Central. Vulnerabilidades foram detectadas evidenciando esgotamento dos investimentos e restrição financeira das empresas, além de redução na capacidade de poupança das famílias. Observou-se, ainda, que o resto do mundo vem recebendo uma parcela significativa da poupança brasileira.
\end{abstract}

Palavras-chave: Fluxo de fundos. Matriz de ativos e passivos. Desequilíbrios financeiros. Sistema de contas nacionais. Instrumentos financeiros.

\section{THE ORIGINS OF RECENT BRAZILIAN ECONOMIC DEFAULTS: COME FROM REAL ECONOMIC OR FINANCIAL ISSUES?}

\section{ABSTRACT}

The paper aims to understand the origins of the recent declines in the product of the Brazilian economy (defaults), observed in the years 2009, 2015 and 2016, checking whether they are related to the real economy or to purely financial transactions and seeks to discuss the factors related to detected causes. A flow of funds analysis was applied, which allowed us to observe that financial transactions mirrored real transactions in all years, except in 2008, showing that the causes of defaults are strongly related to real economy factors. Changes in the structural position of the institutional sectors have evidenced the loss of the government's "policy space" and that financial companies have improved their role as financial intermediaries with the encouragement of the Central Bank. Vulnerabilities were detected, evidencing the reduction in the saving capacity of families, depletion of investments and financial restriction of non-financial companies, and also, it was observed that the rest of the world has been receiving a significant portion of Brazilian savings.

Keywords: Flow of funds. Asset liability matrix. Financial imbalance. System of national account. Financial instruments.

\footnotetext{
${ }^{1}$ Autora correspondente. Universidade Federal Fluminense (UFF) - Departamento de Administração - Escola de Ciências Sociais e Humanas (PUV), Polo Universitário de Volta Redonda. Av. dos Trabalhadores, 420 - Villa Santa Cecília. CEP 27255-125. Volta Redonda/RJ, Brasil. http://lattes.cnpq.br/0441431053844250. http://orcid.org/0000-0002-8703-3985. erikabkw@yahoo.com.br

2 Okayama University, Japan. https://orcid.org/0000-0003-1338-3066.jiyoungkim8255@gmail.com
} 
Como destacado por De Paula e Pires (2017), a economia brasileira recente apresentou períodos intercalados entre crescimento e redução da produção. A manutenção do tripé macroeconômico (taxa de câmbio flutuante livre, meta de inflação e meta fiscal) estabelecido como política econômica desde 1999 e a liquidez do mercado internacional, que se ampliou a partir de 2004, propiciaram o crescimento da economia brasileira a partir de 2004; crescimento que foi freado pela crise do subprime em 2008. A flexibilização do tripé macroeconômico, que ficou conhecida como a nova matriz econômica, juntamente com a retomada do crescimento mundial, permitiu a recuperação da economia brasileira em 2010, entretanto não foi suficiente para sua manutenção. $A$ partir de 2011 o produto cresceu, porém a taxas decrescentes. Essa trajetória de crescimento foi alterada em 2014, chegando a ser interrompida em 2015. Como será visto, o Produto Interno Bruto (PIB) apresentou variação negativa de $0,1258 \%$ no volume do PIB em 2009, e nos anos de 2015 e 2016 houve variação negativa de 3,7693\% e 3,5947\% no volume do PIB, respectivamente (IBGE, 2018).

Este trabalho visa a compreender as causas dos "defaults" econômicos no Brasil (considerando como default a variação negativa no volume do PIB ocorrida nos anos de 2009, 2015 e 2016). Pretende-se apresentar a situação econômica brasileira, verificar se os defaults tiveram suas origens na economia real ou nas transações puramente financeiras, como também discutir os fatores que estariam relacionados a estas variações.

Utiliza-se a metodologia de análise de Fluxo de Fundos (Flow-of-Funds - FOF), a qual permite a observação das relações reais e financeiras, auxiliando na compreensão dos desequilíbrios econômicos. Indicadores do poder de dispersão de fundos possibilitam a visualização do papel de cada setor na economia, a observação de desequilíbrios quando há variações bruscas no papel desempenhado pelos setores, como também a análise da evolução da dispersão da discrepância entre ativos e passivos. A decomposição estrutural da variação na discrepância permite verificar se as origens de uma crise foram em razão de transações reais ou financeiras (TSUJIMURA; MIZOSHITA, 2003).

Para aplicar o método de análise de FOF na economia brasileira foram desenvolvidas matrizes FOF anuais para o período de 2004 a 2015, a partir dos Balanços Patrimoniais do Banco Central do Brasil (BCB 2004-2015) e das contas do Balanço Patrimonial Financeiro do Brasil, disponibilizados pelo Instituto Brasileiro de Geografia e Estatística (IBGE, 2011a) e pela Organização para a Cooperação e o Desenvolvimento Econômico (OCDE, 2009-2015).

Mesmo com defasagem nos dados (último ano disponível da série quando da realização deste trabalho era o ano de 2105), o método de análise de FOF foi preciso ao indicar aumentos na dispersão da discrepância nos anos que precedem os defaults. A análise diagnóstica fornecida pelos índices FOF revelou desequilíbrios estruturais na evolução da posição financeira dos setores institucionais, destacando as contribuições da metodologia.

Após esta introdução, o trabalho segue com a apresentação dos fundamentos da análise de FOF: como ela pode ajudar na compreensão de crises e uma breve contextualização da economia brasileira no período de 2004 a 2015. Em seguida, apresenta-se a metodologia, a base de dados e os resultados da aplicação da metodologia de FOF para a economia brasileira. Nas considerações finais, destacam-se as principais constatações, as limitações do trabalho e sugestões para trabalhos futuros. 


\section{ANÁLISE DE FLUXO DE FUNDOS E CRISE DO SUBPRIME}

A análise de Fluxo de Fundos (Flow of Funds ${ }^{3}$ - FOF), proposta por Copeland (1952), apresenta influências de várias vertentes, entre as quais duas se destacam: o desenvolvimento das contas nacionais e o debate sobre os ciclos econômicos. Compreendendo que os fundos são o "sangue vital" que circula na economia, Copeland (1952) divide a economia em setores institucionais organizando-os para evidenciar como cada setor faz/recebe pagamentos de/para os demais setores (relação "pagador-recebedor" ou "de quem para quem"). Em um sistema de partidas dobradas, os pagamentos feitos por setor são registrados em um lado e os recebimentos no outro. Seguindo as análises de Mitchell (1944), Copeland (1952) proveu um sistema compreensivo de medição do fluxo de fundos, organizado para interpretar as estatísticas econômicas na forma de balanços financeiros dos setores institucionais que destacam o relacionamento entre os setores, fornecendo as medidas agregadas das transações necessárias para identificar as influências da economia não financeira nos mercados financeiros e a recíproca influência do mercado financeiro sob a oferta e demanda por bens e serviços, poupança e investimento.

Copeland (1952) descreve seu trabalho como uma extensão da abordagem da contabilidade social proposta por Hicks (1942), aprimorando-a ao incluir as transações financeiras, e destaca que as vantagens dessa abordagem é permitir a visualização das entradas e saídas de fundos de forma desagregada para cada setor. Taylor (1991) ressalta a contribuição significativa de Copeland para o desenvolvimento das contas econômicas, mostrando que o Sistema de Contas Nacionais (System of National Accounts - SNA) mantém semelhanças com as contas de FOF. Ambas são baseadas na noção da economia como um circuito, entretanto as contas de FOF permitem analisar os movimentos de débito e crédito que não fazem parte dos conceitos de produção e distribuição da renda que constam no SNA.

As contas de FOF também apresentam similaridades com as tabelas de Insumo-Produto (IP) de Leontief (1936); ambas focam na análise "de quem para quem", embora duas diferenças sejam destacadas: enquanto no sistema de IP observa-se o fluxo de bens e serviços, nas contas FOF observa-se o fluxo financeiro; e, enquanto as contas de IP mantêm o foco em indústrias (setores produtivos), as contas de FOF são organizadas no conceito de setores institucionais (conjunto de entidades legais como indivíduos e corporações agregados em famílias, empresas e governo).

A análise de FOF desenvolveu-se amplamente nas décadas de 60 e 70 do século 20, e Cohen (1972) lista cerca de 250 trabalhos que abordam FOF neste período, mas, nos anos seguintes, houve redução em sua utilização. De Bonis e Pozzolo (2012) destacam que o abandono da abordagem keynesiana, o crescimento da ênfase nos fundamentos microeconômicos, as dificuldades encontradas nos modelos "macroeconométricos", incluindo a avaliação da interação entre os setores real e financeiro, a redução

\footnotetext{
${ }^{3}$ Taylor (1991) explica que a mudança do nome original "System of Moneyflow" para "System of Flow of Funds" deve-se à intenção do Federal Reserve em estabelecer maior clareza e evitar ambiguidades, pois o termo "Moneyflow" poderia ser confundido com fluxo de caixa (termo utilizado na contabilidade corporativa) quando da publicação da primeira versão do fluxo de fundos para a economia Norte Americana em 1955.
} 
do uso da programação dos fluxos financeiros no planejamento econômico e o crescimento do uso do controle de preços via metas inflacionárias para acessar o equilíbrio de mercado, foram as principais causas da redução no uso da abordagem de FOF.

Em razão das recentes crises financeiras, como a crise dos países asiáticos no final da década de 90 e a crise do subprime (2007-2009), a necessidade de analisar as relações entre a economia real e o setor financeiro é ansiada, estimulando o ressurgimento da análise de FOF nos anos recentes como uma importante fonte de dados para análise econômica, provendo informações da renda, gastos, financiamento e decisões de portfólio financeiro dos setores institucionais de forma integrada.

Atualmente, esforços vêm sendo feitos para compilar as contas financeiras pela OCDE, pelo Instituto Nacional de Estatística da União Europeia (Eurostat) e por Bancos Centrais nacionais, tais como Federal Reserve (dos EUA) e o Banco do Japão.

Palumbo e Parker (2009) destacam a importância do monitoramento dos fluxos e dos estoques de ativos e passivos financeiros para a condução da política econômica na tentativa de garantir estabilidade financeira. As contas FOF fornecem uma grande quantidade de informações sobre a condição financeira de um país e constituem uma ferramenta valiosa para sinalizar os desequilíbrios dos setores que podem levar a dificuldades financeiras ou à insolvência, e destacar as fraquezas potenciais que poderiam prejudicar a estabilidade financeira de um país, caso fosse atingido por um choque exógeno.

A grande vantagem das contas financeiras é que mostram as ligações entre os padrões de estoque financeiro e os padrões de fluxos financeiros entre os diversos setores da economia e entre a economia nacional com o resto do mundo. Como destaca De Bonis e Pozzolo (2012), o aumento maciço da integração financeira internacional, a redução da poupança das famílias e o crescimento do passivo líquido das empresas não financeiras (condições existentes no período em que antecedeu a crise financeira do subprime), são características que geram vulnerabilidade econômica e que podem ser observadas a partir da análise de FOF.

Dentre as causas da crise do subprime, De Bonis e Pozzolo (2012) destacam a mudança estrutural ocorrida nos mercados financeiros, como a inovação financeira, a desregulamentação e o aumento da integração financeira entre diversos países. A inovação financeira, apoiada por mudanças na tecnologia, permitiu aos bancos a criação de produtos estruturados que transformaram ativos de risco em títulos aparentemente seguros, caracterizados por níveis muito elevados de complexidade e opacidade. A desregulamentação aumentou a concorrência no setor financeiro, removendo barreiras à entrada e reduzindo os padrões de supervisão. Ao mesmo tempo, a demanda foi estimulada por fundos de hedge, firmas de private equity, bancos europeus e novos investidores de países, como a China e outros do Leste Asiático, que tiveram grande crescimento e entraram no mercado financeiro com grandes montantes de liquidez para investir. O fator complicador foi que grande parcela da demanda para os produtos estruturados, denominados em dólares, foi financiada a curto prazo, levando a um rápido aumento dos ativos e passivos externos brutos desses países. 
A falta de transparência dos títulos (os produtos estruturados) afetou a carteira de ativos de todas as instituições financeiras, e o aumento da demanda por ativos "seguros" causou o crescimento da alavancagem.

O nível de endividamento foi fundamentalmente importante. Como apontam Palumbo e Parker (2009), a dívida doméstica nos EUA aumentou de forma relevante nos anos anteriores à crise, concomitantemente à redução nas taxas de poupança das famílias, que mudaram sua posição de um setor poupador (ou credor) para o maior setor investidor (ou devedor). Assim que os preços das casas pararam de aumentar, tornou-se impossível continuar a fórmula generalizada de renovação dos empréstimos hipotecários.

A queda nos preços das casas, que causou o declínio no valor agregado dos empréstimos hipotecários subprime concedidos às famílias excessivamente alavancadas, foi o gatilho para um grande ajuste no preço dos produtos estruturados: a queda no valor das carteiras de empréstimos dos bancos foi rapidamente transmitida ao preço dos produtos estruturados, levando a grandes mudanças no valor dos ativos totais de todo o setor financeiro (PALUMBO; PAKER, 2009).

$\mathrm{O}$ passivo do setor financeiro também foi drasticamente afetado pelos ajustes de valor que ocorreram durante a crise. Embora a heterogeneidade das instituições do setor financeiro tenha dificultado a detecção de um aumento constante na alavancagem, Palumbo e Parker (2009) salientam que os passivos agregados do setor aumentaram mais rapidamente do que seus ativos em meados dos anos 2000, e os bancos comerciais de muitos países experimentaram uma maior alavancagem entre 2000 e 2006.

Em condições normais, o balanço de um agente econômico está em equilíbrio quando o valor dos ativos (totais) é maior ou igual ao de seus passivos. Mudanças muito rápidas nas posições financeiras precisam ser monitoradas de perto, uma vez que podem esconder desequilíbrios e descasamentos de prazos. Por isso, um olhar atento sobre a sustentabilidade dos preços dos ativos reais e financeiros é essencial. De Bonis e Pozzolo (2012) reforçam que é fundamental analisar a evolução dos fluxos e dos estoques financeiros, pois a evolução das diferenças estruturais no valor dos ativos e passivos financeiros, ampliadas pela alavancagem e integração excessiva, tiveram um efeito relevante no desdobramento da crise do subprime. Não fossem esses fatores, a queda no preço dos ativos reais teria afetado as companhias hipotecárias e se encerraria ali, sem grandes impactos nas demais instituições do setor financeiro e sem se espalhar por todas as economias mundiais.

\section{EVOLUÇÃO RECENTE DA ECONOMIA BRASILEIRA}

A crise do subprime atingiu a economia brasileira em um momento de auge do crescimento econômico, o qual havia se iniciado em 2005, causando uma mudança na trajetória de crescimento em 2008 e levando à redução do volume do produto total da economia em 2009. No ano de 2010, foi observada uma retomada no crescimento, mas, nos anos seguintes, a tendência não se confirmou, havendo crescimento do produto, porém com taxas decrescentes. Em 2013 ocorreu uma elevação no crescimento, entretanto, em 2014, o crescimento foi bem menor que no ano anterior, e nos anos de 2015 e 2016 houve retração da produção econômica. A Figura 1 apresenta a taxa de crescimento anual do volume do produto interno bruto (PIB) entre 2004 e 2016. 
Figura 1 - Variação percentual anual do volume do PIB - Brasil, 2005 a 2016

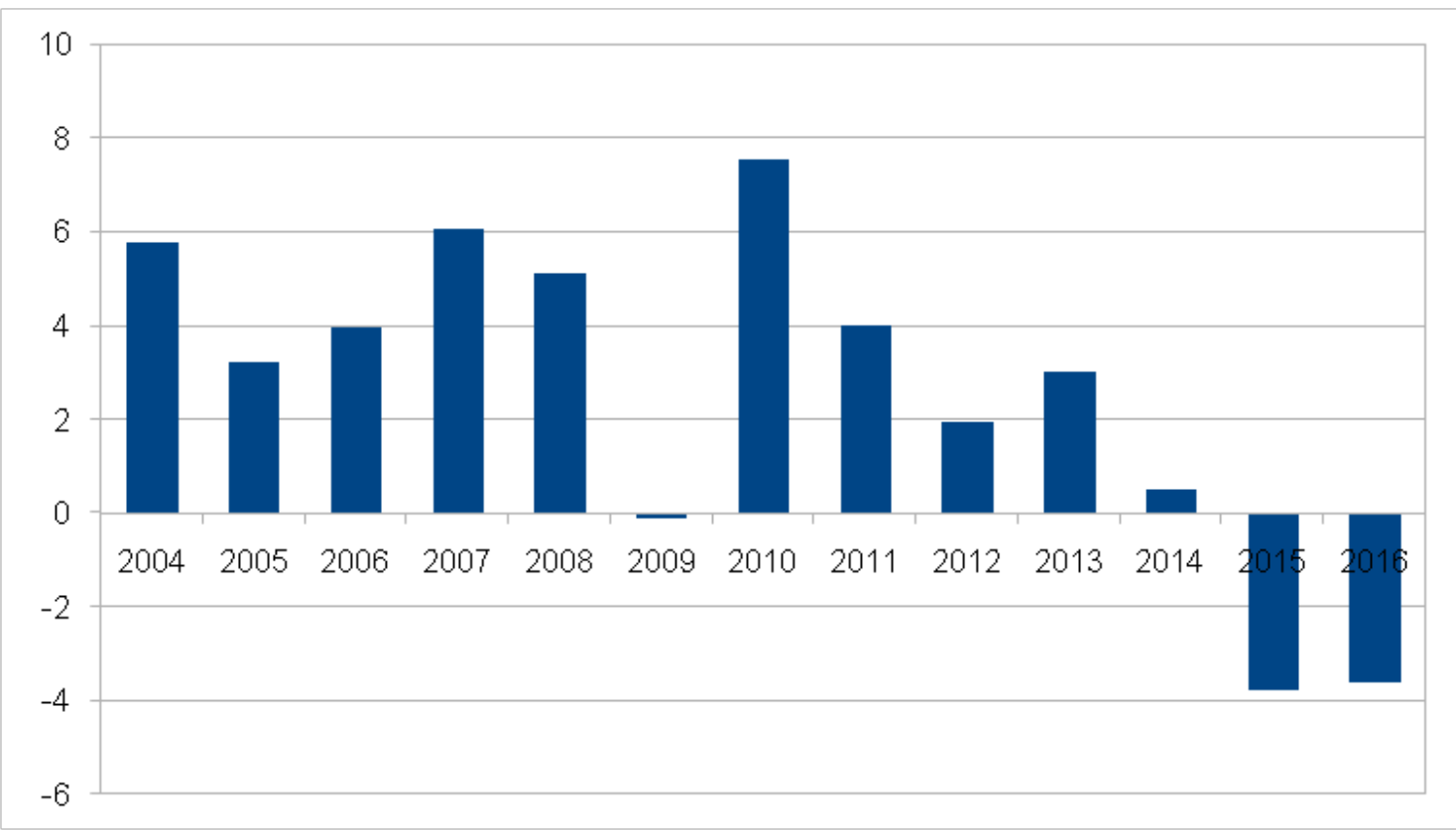

Fonte: IBGE (2018). Diretoria de Pesquisas. Coordenação de Contas Nacionais.

Até o ano de 2007 a política econômica no Brasil foi conduzida com alta taxa de juros e amplo superávit primário, mantendo as bases do tripé econômico adotado desde 1999, constituído pelo regime de metas de inflação ${ }^{4}$, metas de superávit primário e regime de câmbio flutuante. O crescimento ocorrido a partir de 2004 foi estimulado pelo boom de commodities em um primeiro momento e pelo aumento no consumo das famílias em um segundo momento. O setor público passou de uma posição de devedor líquido para credor líquido, no cenário internacional, em razão do grande influxo de capitais, do superávit comercial e da reestruturação da dívida externa pública, que permitiu ao Banco Central do Brasil (BCB) acumular reservas internacionais (DE PAULA; PIRES, 2017).

A partir de 2003 inicia-se uma fase de expansão da oferta de crédito ao setor privado, principalmente com o crédito à pessoa física. A aceleração no ritmo de crescimento do produto e dos investimentos, observada em 2007, exigiu maior volume de recursos para as empresas, tanto para o financiamento de longo prazo quanto para o capital de giro. Esta demanda foi suprida via emissão de ações e títulos privados no mercado de capitais e via contratação de linhas de crédito doméstico e no exterior. Com o aprofundamento da crise do subprime em 2008, as linhas de crédito externo e o fluxo de capitais foram limitados, e, consequentemente, as empresas brasileiras e multinacionais que operam no país passaram a recorrer ao mercado de crédito bancário doméstico, o que aumentou a concorrência nesse mercado (FREITAS, 2009).

Ao final de 2008, o Banco Central do Brasil (BCB) aumentou a taxa Selic, avultando a rentabilidade dos títulos públicos federais e desencadeando a realocação das carteiras de aplicações financeiras para os títulos públicos em detrimento das ações e dos títulos de dívida privada. O mercado de crédito bancário passou a sofrer os efeitos do proble-

\footnotetext{
${ }^{4}$ A taxa do Sistema Especial de Liquidação e Custódia (taxa Selic), sistema no qual são operados os títulos públicos federais, é o principal instrumento para controle da inflação.
} 
ma de "empoçamento" de liquidez no mercado interbancário doméstico, acarretando aumento do custo de captação das empresas e dos bancos, principalmente os de médio e pequeno porte (FREITAS, 2009).

Segundo Araújo e Gentil (2011), em 2009 as políticas creditícias anticíclicas instituídas para suprir a liquidez do setor bancário foram: linha temporária de crédito para as exportações e estímulo à expansão do crédito por parte dos bancos públicos. O governo também criou políticas fiscais anticíclicas, como a redução do imposto sobre produtos industrializados (IPI) para automóveis, eletrodomésticos e produtos de construção, aumento do período de concessão do seguro-desemprego e criação de um programa de construção de moradia popular ("Minha Casa Minha Vida"). O Banco Central do Brasil $(B C B)$ realizou intervenções no mercado cambial para conter a desvalorização da moeda brasileira, no entanto manteve a taxa de juros Selic elevada até janeiro de 2009, contrastando com a política fiscal anticíclica e com a política creditícia dos bancos públicos.

Ao final do ano de 2009 e no ano de 2010 houve crescimento do consumo, dos investimentos e das exportações. Como destacado por De Paula e Pires (2017), o fator relevante para esta retomada de crescimento foi o aumento das exportações, estimulado, principalmente, pela ampliação da economia chinesa em 2009 e pela recuperação da economia mundial em 2010, o que gerou aumento do fluxo de capitais e valorização da moeda brasileira.

Ao final de 2009 o governo estabeleceu um imposto sobre operações financeiras (IOF) em cima das aplicações em ações e de renda fixa de não residentes, com o objetivo de estabelecer o controle de capitais. O fluxo de capitais, porém, continuou a crescer e, ao final do ano seguinte (2010), foram estabelecidas medidas macroprudenciais, como o aumento da taxa de juros e a definição de metas fiscais nos níveis observados antes da crise do subprime. Essas políticas econômicas tinham o intuito de reduzir a demanda agregada, conter a inflação e evitar o aumento do risco sistêmico em razão do crescimento do fluxo de capitais.

No período subsequente (2011 a 2014), entretanto, observa-se redução na taxa de crescimento médio da economia mundial por causa da crise do Euro, fraca recuperação norte-americana e desaceleração dos países emergentes, fatores que levaram à redução do fluxo de capitais, das exportações e aumento das importações. O governo atuou com redução drástica na taxa Selic e desvalorização cambial entre 2011 e 2012. Ao final de 2011 foram adotadas políticas fiscais, como a isenção do IPI sobre bens de capital e a desoneração da folha de pagamento de setores intensivos em mão de obra, mas, como não surtiram o efeito desejado de estimular o crescimento, em 2012 houve ampliação da desoneração da folha de pagamento para outros setores, redução do IPI de alguns bens duráveis, postergação do recolhimento do PIS/Cofins e redução da alíquota do IOF sobre operações de crédito a pessoas físicas. Essas medidas faziam parte da "nova matriz econômica" (DE PAULA; PIRES, 2017).

Observou-se, contudo, redução na taxa de crescimento econômico, com destaque para o investimento. Como orienta Oreiro (2017), a nova matriz econômica não se mostrou capaz de gerar uma aceleração permanente no crescimento da economia, pois as medidas não foram suficientes para estimular o crescimento da taxa de retorno do capital. Oreiro (2017) destaca que a redução dos investimentos é consequência da queda na taxa de retorno do capital, fator que influencia na formação das expectativas. A taxa de retorno do capital das empresas brasileiras foi se reduzindo a partir de 2011 , influenciada, principalmente, pela queda da margem de lucro das empresas em virtude 
do aumento do custo da mão de obra que não pôde ser repassado para os preços dos produtos em razão da concorrência com os produtos importados, cujos preços relativos estavam reduzidos pela desvalorização da taxa de câmbio.

Em 2013 algumas medidas de incentivo fiscal foram mantidas, porém o BCB voltou a elevar a taxa Selic. Em 2014 verificou-se uma tendência de redução no "espaço de política" em razão da deterioração fiscal com o aumento do déficit nominal, causado pela queda das receitas tributárias e pelo impacto dos juros sobre a dívida pública. De Paula e Pires (2017) afirmam que os incentivos fiscais não beneficiaram as empresas industriais domésticas e vazaram para o exterior, mostrando que o produto industrial parou de crescer desde $2010 \mathrm{em}$ consequência do aumento do coeficiente de importações. Assim, os autores concluem que os ajustes fiscais, somados à desvalorização da moeda e ao aumento da taxa Selic ocorridos em 2015, contribuíram para reduzir ainda mais o crescimento econômico.

\section{METODOLOGIA}

Foram utilizados dois grupos de indicadores da metodologia de fluxo de fundos (FOF): indicadores do poder de dispersão (Power of Dispersion Index - PDI) e o indicador de dispersão da discrepância (Dispersion of Discrepancy Index - DDI), sobre o qual foi feita uma decomposição (Structural Decomposition Analysis - SPA).

A aplicação da metodologia implica a construção de duas matrizes de FOF a partir das tabelas de ativos e tabelas de passivos extraídas dos Balanços Patrimoniais Financeiros Nacionais. Stone (1966) propõe uma matriz de FOF construída com base no fluxo de passivos, e Klein (1983) uma matriz de FOF construída com base no fluxo de ativos. Ambas foram utilizadas de forma conjunta ${ }^{5}$.

As tabelas de ativos (e as tabelas de passivos) são compostas pelos ativos (passivos) financeiros detidos pelos setores institucionais e excesso de passivos (ativos). Quando há excesso de passivos na tabela de ativos o resultado da economia real é uma necessidade de financiamento, ou seja, o investimento é maior que a poupança. Quando há excesso de ativos na tabela de passivos o resultado da economia real é uma capacidade de financiamento, ou seja, a poupança foi maior que os investimentos ${ }^{6}$.

A partir das duas matrizes de coeficientes técnicos das matrizes de FOF, são calculadas as matrizes inversas de Leontief, definidas de acordo com as equações 1 e 2:

$$
\begin{array}{ll}
A^{S}=\left(I-C^{S}\right)^{-1} & \text { Eq. } 1 \\
A^{K}=\left(I-C^{K}\right)^{-1} & \text { Eq. } 2
\end{array}
$$

Onde:

$A^{S}=$ é a matriz inversa de Leontief, construída a partir da fórmula de Stone;

$A^{K}=$ é a matriz inversa de Leontief, construída a partir da fórmula de Klein;

$\mathrm{C}^{S}=$ é a matriz de coeficiente técnicos, obtida pela divisão dos elementos da matriz FOF a partir da fórmula de Stone pelos respectivos totais coluna;

$\mathrm{C}^{\mathrm{K}}=$ é a matriz de coeficiente técnicos, elaborada pela divisão dos elementos da matriz FOF a partir da fórmula de Klein pelos respectivos totais coluna;

\footnotetext{
${ }^{5}$ Para maior detalhamento da forma de elaboração das matrizes de ativos e passivos e das matrizes de fluxos de fundos, ver Tsujimura e Mizoshita (2003).

${ }^{6}$ Para um detalhamento da relação das contas econômicas com as contas financeiras e contas de patrimônio financeiro ver Feijó e Ramos (2013) e Tsujimura e Tsujimura (2018).
} 


\section{Indicador do Poder de Dispersão (Power of Dispersion Index - PDI)}

O PDI mede os efeitos diretos e indiretos da obtenção de fundos pela fórmula de Stone (1966) e pelo emprego de fundos por meio da fórmula de Klein (1983).

O cálculo do PDI é feito a partir das inversas de Leontief das matrizes de FOF. As equações 3 e 4 expressam os cálculos para as fórmulas de Stone e de Klein, respectivamente:

$$
\begin{aligned}
\omega_{j}^{K} & =\frac{\sum_{i=1}^{m} a^{s_{i j}}}{\frac{1}{m} \sum_{j=1}^{m} \sum_{i=1}^{m} a^{s_{i j}}} \\
\omega_{j}^{K} & =\frac{\sum_{i=1}^{m} a^{s_{i j}}}{\frac{1}{m} \sum_{j=1}^{m} \sum_{i=1}^{m} a^{s_{i j}}}
\end{aligned}
$$

Eq. 4

Onde: $a^{S} i j$ são os elementos da inversa de Leontief da matriz FOF pela fórmula Stone $\left(A^{S}\right)$, e $a^{\mathrm{K}} \mathrm{ij}$ são os elementos da inversa de Leontief da matriz FOF pela fórmula Klein $\left(A^{K}\right)$.

Segundo Tsujimura e Mizoshita (2003), o PDI calculado a partir da fórmula Stone, doravante PDI-FR (fund raising - FR), indica a demanda total por fundos na economia, induzida por um aumento da necessidade por fundos em um determinado setor, o que ocorre quando o setor tem excesso de investimento em relação à sua poupança.

Por outro lado, o PDI, pela fórmula Klein, doravante denominado PDI-FE (Fund Employment - FE), mostra os efeitos do espalhamento dos fundos quando há variações na oferta de recursos. A oferta de fundos no total da economia induzida por aumentos na oferta de fundos de um determinado setor, ocorre quando o setor tem excesso de poupança em relação aos seus investimentos.

Por serem calculados de forma análoga aos multiplicadores insumo-produto, os PDIs consideram as inter-relações financeiras entre os diversos agentes econômicos. Como destacado por Palumbo e Parker (2009), o aumento da integração financeira foi uma das principais causas de a crise do subprime ter se espalhado rapidamente por todas as economias. Os PDIs do resto do mundo permitem analisar a inter-relação da economia com o exterior.

Adicionalmente, uma mudança brusca na posição relativa de um setor, revelada por variações no PDI, indica vulnerabilidades e desequilíbrios. A posição relativa dos setores institucionais da economia brasileira foi determinada pela combinação do PDI-FR e do PDI-FE em um gráfico em que o PDI-FR é registrado no eixo horizontal e o PDI-FE no eixo vertical. Com essa combinação, quatro posições no gráfico são possíveis, conforme exposto na Figura 2.

Figura 2 - Gráfico da posição econômica a partir da combinação do PDI-FR e PDI-FE

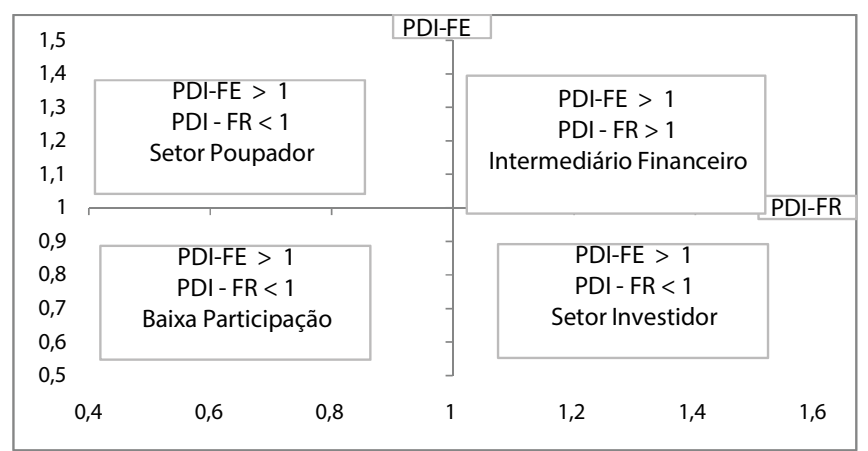

Fonte: Elaboração própria a partir de Tsujimura e Mizoshita (2003). 


\section{Indicador da Dispersão da Discrepância (Discrepancy of Dispersion Index - DDI)}

O DDI é a diferença entre a dispersão de ativos e a dispersão de passivos. A dispersão de ativos é obtida pela soma dos elementos da inversa de Leontief da matriz FOF elaborada a partir da fórmula de Klein, e a dispersão de passivos é obtida pela soma dos elementos da inversa de Leontief da matriz FOF elaborada desde a fórmula de Stone. A dispersão do passivo é expressa na equação 5 e a dispersão do ativo na equação 6 . A dispersão de passivos, subtraída da dispersão de ativos, resulta no índice de dispersão da discrepância (DDI), conforme apresentado na equação 7.

$$
\begin{aligned}
& w^{S}=\sum_{i=1}^{m} \sum_{j=1}^{m} a^{S} i j \\
& w^{K}=\sum_{i=1}^{m} \sum_{j=1}^{m} a^{K} i j \\
& w^{S-K}=w^{S}-w^{K}
\end{aligned}
$$

Onde: $W^{S}$ é o índice de dispersão de passivos, $W^{K}$ é o índice de dispersão de ativos e $W^{S-K}$ é o DDI.

O DDI mostra a diferença entre a oferta e a demanda de fundos. O aumento da dispersão revela evolução desequilibrada entre os preços de ativos e passivos, indicando riscos sistêmicos e vulnerabilidades relacionados tanto à economia real quanto aos fluxos financeiros. Como apontam De Bonis e Pozzolo (2012), a evolução nos preços dos ativos reais e financeiros precisam ser monitorados, e a evolução desordenada do valor dos ativos e passivos foi uma das causas da crise do subprime.

As mudanças na matriz inversa de Leontief da matriz FOF podem ser divididas em duas categorias: i) a soma de cada elemento da matriz de coeficientes e ii) a distribuição entre os coeficientes ${ }^{7}$. A variação do DDI, portanto, pode ser decomposta em dois componentes por meio de uma decomposição estrutural (Structural Path Decomposition SPD).

A equação 8 apresenta a forma de cálculo da SPD:

$$
\begin{aligned}
& \Delta w^{S-K}{ }_{t, t}=\left\{\frac{\left(w^{K}{ }_{t, t}-w^{K}{ }_{t, t-1}\right)+\left(w^{K}{ }_{t-1, t}-w^{K}{ }_{t-1, t-1}\right)}{2}-\frac{\left(w^{S}{ }_{t, t}-w^{S}{ }_{t, t-1}\right)+\left(w^{Y}{ }_{t-1, t}-w^{Y}{ }_{t-1, t-1}\right)}{2}\right\}+\text { Eq. } 8 \\
& \left\{\frac{\left(w^{K}{ }_{t, t}-w^{K}{ }_{t-1, t}\right)-\left(w^{K}{ }_{t, t-1}-w^{K}{ }_{t-1, t-1}\right)}{2}-\frac{\left(w^{S}{ }_{t, t}-w^{S}{ }_{t-1, t}\right)-\left(w^{S}{ }_{t, t-1}-w^{S}{ }_{t-1, t-1}\right)}{2}\right\}
\end{aligned}
$$

onde os subscritos t-1 e t definem o primeiro e o segundo períodos da matriz inversa de Leontief da matriz FOF.

O primeiro termo do lado direito da equação 8 é a parcela atribuída a mudanças na economia real (indica a contribuição da redução ou aumento da poupança e de investimentos), enquanto o segundo termo é o segmento referente a mudanças na estrutura do portfólio financeiro (indica a contribuição das transações puramente financeiras em razão de alterações na alocação na carteira de ativos e passivos).

\footnotetext{
${ }^{7}$ Para um detalhamento do processo de decomposição estrutural, ver Miller e Blair (2009).
} 
Assim, a decomposição permite identificar se a variação da discrepância em um determinado período foi causada pelas transações financeiras ou pelo excesso (ou falta) de investimentos produtivos em infraestrutura, máquinas e equipamentos.

\section{BASE DADOS}

Foram desenvolvidas as matrizes FOFs para a economia brasileira para o período de 2004 a 2015, a partir das Contas de Balanço Patrimonial Financeiro (Financial Balance Sheet Account - FBSA) do Brasil e dos Balanços Patrimoniais do Banco Central do Brasil (BCB).

Para o período de 2004 a 2009, as FBSAs do Brasil foram publicadas como anexo complementar das Contas Econômicas Integradas pelo BCB em conjunto com o Instituto Brasileiro de Geografia e Estatística (IBGE, 2011b). A publicação, no entanto, foi descontinuada ${ }^{8}$.

Para o período de 2009 a 2015, os dados estavam disponíveis na OCDE. Os dados de 2015 eram os mais recentes publicados até o momento da elaboração deste trabaIho. Foi utilizada a FBSA que segue o modelo SNA 2008, dados não consolidados (OCDE, 2009-2015).

Os ativos e passivos financeiros foram organizados em seis instrumentos financeiros (numerários e depósitos; títulos, exceto ações; empréstimos e financiamentos; ações e outras participações de capital; reservas técnicas de seguros; e outros débitos e créditos) mantidos por seis setores institucionais. Os cinco setores institucionais incluídos na FBSA são: empresas não financeiras, empresas financeiras, famílias, administração pública e o resto do mundo. Acrescentou-se o Banco Central do Brasil desagregando os ativos e passivos financeiros das empresas financeiras em duas contas: "BCB", representando o Banco Central do Brasil (BCB) e "empresas financeiras", representando todas as demais instituições financeiras. Isso foi feito subtraindo o estoque de ativos e passivos constante nos Balanços Patrimoniais do $B C B$ do estoque de ativos e passivos do agregado de empresas financeiras apresentado na FBSA. A descrição detalhada dos instrumentos financeiros e dos setores institucionais é disponibilizada na Nota Metodológica n. 8 (IBGE, 2011b).

Do Balanço Patrimonial do BCB foram utilizados os dados anuais de 2004 a 2015 (exercícios findos em 31 de dezembro de cada ano). A elaboração do Balanço Patrimonial do BCB segue o Plano Geral de Contas do Banco Central (PGC). A partir do PGC foi construído um plano de codificação entre as contas do FBSA e as contas do Balanço Patrimonial.

\section{RESULTADOS}

Com a análise do indicador de dispersão da discrepância (DDI) entre os ativos e passivos, observou-se que houve aumento significativo da discrepância em 2008, seguido por um declínio acentuado em 2009. De 2010 a 2013 a discrepância diminuiu contínua e gradualmente. Em 2014 houve novamente aumento seguido de declínio em 2015.

\footnotetext{
${ }^{8}$ Atualmente as Contas de Patrimônio Financeiro e as Contas Financeiras vêm sendo divulgadas em conjunto com as Contas Econômicas Integradas pelo IBGE.
} 
A dispersão de ativos, a dispersão de passivos, o DDI, a variação anual do DDI, a decomposição estrutural da variação do DDI (SPD), a média do período e o desvio padrão, são apresentados na Tabela 1 para o período de 2004 a 2009 e na Tabela 2 expõe-se os dados para o período de 2010 a 2015.

Tabela 1 - Dispersão da discrepância e decomposição - Brasil, 2004 a 2009

\begin{tabular}{|c|c|c|c|c|c|c|}
\hline \multirow{2}{*}{$\begin{array}{l}\text { Ano/ Indica- } \\
\text { dor }\end{array}$} & \multirow{2}{*}{$\begin{array}{c}\text { Dispersão de } \\
\text { Ativos }\end{array}$} & \multirow{2}{*}{$\begin{array}{l}\text { Dispersão de } \\
\text { Passivos }\end{array}$} & \multirow[b]{2}{*}{ DDI } & \multirow{2}{*}{$\begin{array}{l}\text { Variação do } \\
\text { DDI }\end{array}$} & \multicolumn{2}{|c|}{ SPD } \\
\hline & & & & & $\mathrm{ER} \%$ & MF\% \\
\hline 2004 & 40,16 & 34,64 & 5,52 & - & - & - \\
\hline 2005 & 45,02 & 38,65 & 6,37 & 0,85 & 56 & -44 \\
\hline 2006 & 47,01 & 40,38 & 6,63 & 0,27 & 55 & -45 \\
\hline 2007 & 47,54 & 41,5 & 6,04 & $-0,6$ & 59 & -41 \\
\hline 2008 & 61,83 & 51,05 & 10,77 & 4,74 & 40 & 60 \\
\hline 2009 & 52,95 & 47,26 & 5,69 & $-5,09$ & 88 & 12 \\
\hline Média & 49,09 & 42,25 & 6,84 & 0,03 & 59,60 & $-11,60$ \\
\hline Desvio pad. & 6,83 & 5,44 & 1,80 & 3,15 & 15,65 & 41,74 \\
\hline
\end{tabular}

Legenda: DDI = índice de dispersão da discrepância; Variação do DDI = variação anual do DDI; SPD = decomposição estrutural da variação do DDI; ER = Economia Real; MF = Mercado financeiro.

Fonte: IBGE (2011a). Resultados da pesquisa - Elaboração própria.

O crescimento do DDI coincide com os anos em que houve reversão na taxa de crescimento da economia. O DDI elevado em 2008 destaca a intensidade da crise do subprime e seus efeitos na economia brasileira; no ano seguinte, o Brasil experimentou uma redução no volume de produção. O aumento observado no DDI em 2014 também precede um declínio no produto. Como visto, o volume total do PIB da economia brasileira diminuiu nos dois anos seguintes (2015 e 2016). Há, no entanto, uma diferença nas magnitudes dos DDIs de 2008 e de 2014.

A SPD, apresentada nas Tabelas 1 e 2, mostra a contribuição da economia real (derivada de mudanças na oferta e demanda de fundos) e a contribuição do mercado financeiro (derivada de mudanças nos portfólios de ativos e passivos) para a variação do DDI. No primeiro período da análise a SPD mostra que as variações na oferta e demanda de recursos influenciaram mais o DDI (em média 59,6\%) do que as transações puramente financeiras (em média 11,6\%), evidenciando que na maior parte do período os portfólios financeiros se ajustaram para absorver os resultados das contas correntes e de acumulação.

A exceção a esse papel do mercado financeiro de absorção do resultado da economia real ocorre nos anos de 2008 e 2009. No ano de 2008, ano em que se observa a maior discrepância do período e também ano em que a crise financeira do subprime se espalha para os demais países do mundo, as alterações no portfólio financeiro foram responsáveis por $60 \%$ da variação da discrepância entre os ativos e passivos, o que é uma evidência de que a crise financeira impactou a economia brasileira promovendo mudanças nas alocações de portfólio. Como aponta Freitas (2009), a aversão ao risco, somada ao aumento da taxa Selic, estimulou mudanças nos portfólios de investimento dos bancos, os quais direcionaram seus ativos para títulos públicos por serem mais seguros, reduzindo a concessão de crédito ao setor privado que vinha em um ritmo de crescimento, gerando "empoçamento" de liquidez no mercado interbancário. 
Dentre as políticas monetárias para amenizar a restrição de liquidez, os bancos públicos assumiram a missão de conceder crédito ao setor privado, o que pode ser observado pela contribuição positiva das transações financeiras para a redução da variação da discrepância em 2009. A contribuição das operações financeiras para a queda do DDI em 2009, entretanto, foi de $12 \%$, enquanto a contribuição da economia real foi de $88 \%$, demonstrando que as políticas fiscais contribuíram em maior grau do que as políticas monetárias para a redução da discrepância em 2009.

Ao longo de todo o período subsequente à crise financeira, as operações da economia real foram as principais responsáveis pelas mudanças na dispersão da discrepância, contribuindo, em média, com 53\%, enquanto as alterações de portfólio contribuíram, em média, com $47 \%$.

Tabela 2 - Dispersão da discrepância e decomposição - Brasil 2010 a 2015

\begin{tabular}{|c|c|c|c|c|c|c|}
\hline \multirow{2}{*}{$\begin{array}{l}\text { Ano/Indica- } \\
\text { dor }\end{array}$} & \multirow{2}{*}{$\begin{array}{l}\text { Dispersão de } \\
\text { Ativos }\end{array}$} & \multirow{2}{*}{$\begin{array}{l}\text { Dispersão de } \\
\text { Passivos }\end{array}$} & \multirow{2}{*}{ DDI } & \multirow{2}{*}{$\begin{array}{l}\text { Variação } \\
\text { do DDI }\end{array}$} & \multicolumn{2}{|c|}{ SPD } \\
\hline & & & & & ER\% & MF\% \\
\hline 2010 & 38,49 & 35,78 & 2,72 & $-0,4$ & 52 & -48 \\
\hline 2011 & 41,24 & 38,71 & 2,53 & $-0,18$ & 53 & -47 \\
\hline 2012 & 42,38 & 40,1 & 2,28 & $-0,25$ & 55 & -45 \\
\hline 2013 & 44,12 & 41,95 & 2,17 & $-0,11$ & 53 & -47 \\
\hline 2014 & 47,45 & 45,05 & 2,4 & 0,23 & 52 & -48 \\
\hline 2015 & 46,06 & 44,6 & 1,46 & $-0,94$ & 53 & -47 \\
\hline Média & 43,3 & 41,0 & 2,3 & $-0,3$ & 53,0 & $-47,0$ \\
\hline Desvio pad. & 3,0 & 3,3 & 0,4 & 0,4 & 1,0 & 1,0 \\
\hline
\end{tabular}

Legenda: DDI = índice de dispersão da discrepância; Variação do DDI = variação anual do DDI; SPD = decomposição estrutural da variação do DDI; ER = Economia Real; MF = Mercado financeiro.

Fonte: OCDE (2009-2015). Resultados da pesquisa - Elaboração própria.

A partir de 2010 a dispersão na discrepância apresenta uma tendência de redução até 2014, quando ela volta a aumentar. O aumento do DDI, ocorrido em 2014, foi causado principalmente pela economia real (52\%), enquanto a contribuição do mercado financeiro foi de $47 \%$ na direção oposta. Isso indica que as transações financeiras apenas absorveram os resultados econômicos e que o período de recessão recente está diretamente ligado ao setor produtivo, reforçando a proposição de Oreiro (2017), de que ao longo dos últimos anos as empresas vêm reduzindo receita, margens de lucro e investimentos. A economia real é a principal causa dos defaults recentes.

No aumento da discrepância em 2008, a economia real e o mercado financeiro contribuíram positivamente, enquanto para o aumento ocorrido em 2014 somente a economia real contribuiu positivamente. Essa constatação explica a diferença na magnitude entre os DDls de 2008 e de 2014, e indica que, apesar do default de 2009 e os defaults dos anos de 2015 e 2016 terem características bem-distintas, guardam uma relação intrínseca com o lado real da economia, revelando que as condições estruturais do setor produtivo marcam os dois momentos.

Um maior detalhamento dessas relações é obtido pela análise dos indicadores do poder de dispersão de fundos (PDIs). A Figura 3 apresenta as posições relativas dos setores institucionais na economia brasileira sob a perspectiva de FOF, de acordo com os PDIs 
(PDI-FR espalhamento dos fundos a partir da obtenção de fundos e PDI-FE espalhamento dos fundos a partir do emprego de fundos) e sua movimentação entre 2004 e 2009. A Tabela 1 resume as estatísticas descritivas dos PDIs para o período de 2004 a 2009.

A administração pública e as empresas não financeiras são os setores investidores, enquanto as famílias e o resto do mundo são os setores poupadores. O BCB e as empresas financeiras mostram-se em posição estrutural como intermediários financeiros.

No período de 2004 a 2009, a administração pública e o BCB diminuíram suas capacidades de dispersão de recursos tanto para a obtenção de fundos quanto para o seu emprego. Essa redução é mais intensa no ano de 2008, mostrando que a crise financeira afetou a capacidade de ação desses dois agentes em razão da redução na liquidez internacional e da redução da receita do governo, como apontado por De Paula e Pires (2017).

Figura 3 - Gráfico da posição econômica dos setores institucionais no fluxo de fundos, Brasil (2004-2009)

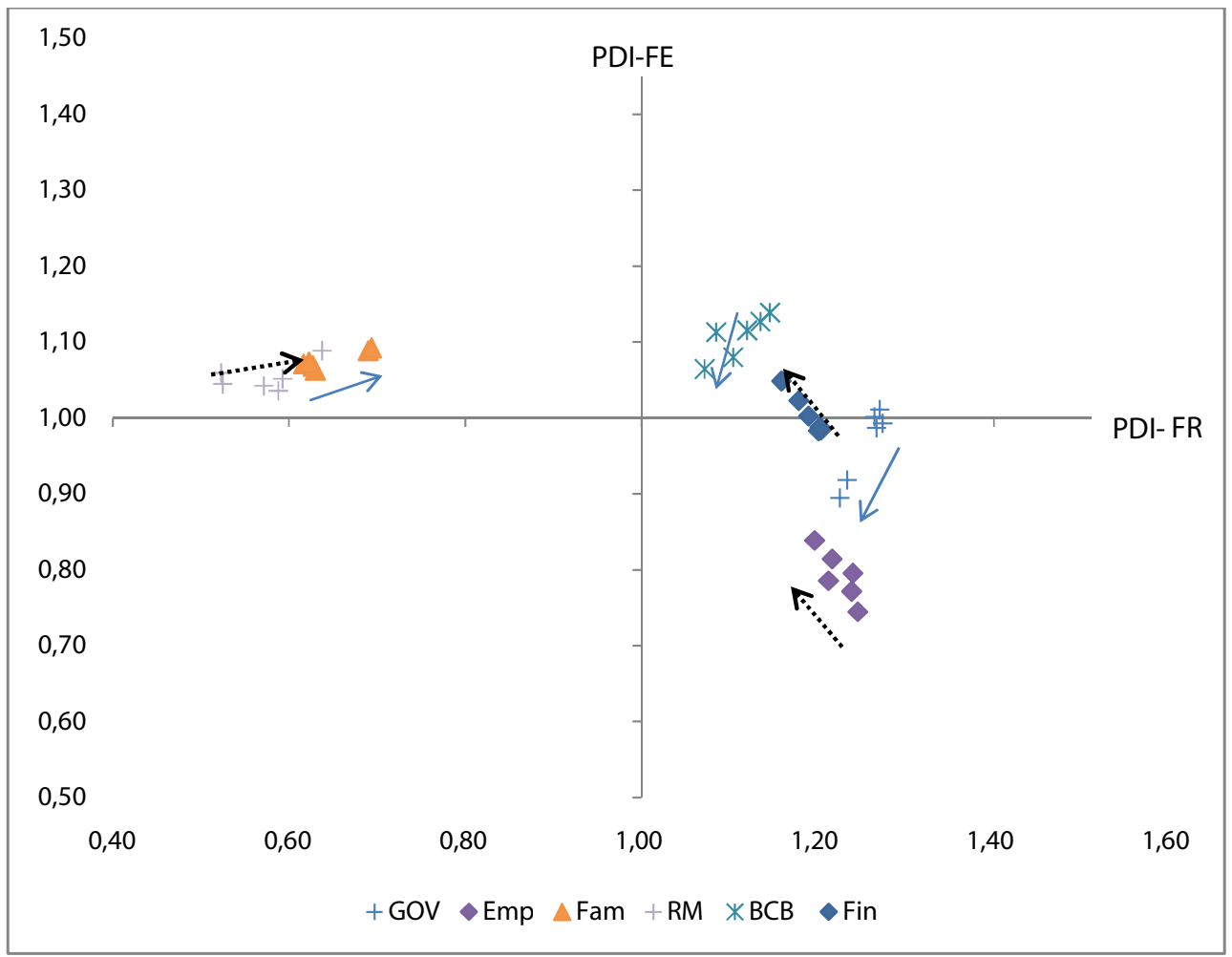

Eixo horizontal $=$ PDI-FR; Eixo vertical $=$ PDI-FE.

Legenda: GOV = Administração Pública; Emp. = Empresas não financeiras; Fam = Famílias; RM = Resto do Mundo, refere-se à economia externa; $\mathrm{BCB}=$ Banco Central do Brasil; Fin = Empresas Financeiras.

Fonte: IBGE (2011a). Resultados da pesquisa. Elaboração própria.

A trajetória apresentada pelas empresas não financeiras merece atenção: elas reduziram sua capacidade de obtenção de recursos e aumentaram o emprego de fundos. As empresas não financeiras representam o setor investidor mais importante em uma economia, mas o aumento no PDI-FE mostra que elas estão aplicando suas poupanças em ativos financeiros no lugar dos ativos fixos. Concomitante a isso, a redução no PDI-FR aponta para uma forte restrição das fontes de financiamento.

As famílias aumentaram continuamente o PDI-FR, que reflete o crescimento da oferta de crédito à pessoa física, relatado por Freitas (2009). Elas também aumentaram o PDI-FE, embora de forma menos intensa. O crescimento na obtenção de recursos 
apresentou uma proporção muito maior que o aumento do emprego dos recursos; mesmo assim, as famílias não modificaram sua posição no cenário econômico ante a crise financeira, mostrando que continuaram a representar o grande setor poupador no Brasil.

Tabela 3 - Estatísticas descritivas da evolução do PDI-FR e PDI-FE - Brasil 2004 a 2009

\begin{tabular}{lrrrrrrr}
\hline PDI-FR & 2004 & 2005 & 2006 & 2007 & 2008 & 2009 & Variação \% \\
Administração Pública (Gov) & 1,2644526 & 1,2703182 & 1,2739563 & 1,2667104 & 1,2252492 & 1,2335025 & $-2,45$ \\
Empresas não financeiras (Ent) & 1,2456148 & 1,2386387 & 1,24003 & 1,2124629 & 1,216314 & 1,1966775 & $-3,93$ \\
Famílias (HH) & 0,6165549 & 0,629992 & 0,6273519 & 0,6228311 & 0,6900282 & 0,6938546 & 12,54 \\
Resto do mundo (ROW) & 0,5233163 & 0,5249687 & 0,5713711 & 0,588087 & 0,6376757 & 0,5930087 & 13,32 \\
Banco Central (BCB) & 1,1459998 & 1,1349669 & 1,0849138 & 1,1202195 & 1,0717616 & 1,104354 & $-3,63$ \\
Empresas financeiras (FF) & 1,2040615 & 1,2011155 & 1,202377 & 1,1896891 & 1,1589712 & 1,1786028 & $-2,11$ \\
\hline PDI-FE & 2004 & 2005 & 2006 & 2007 & 2008 & 2009 & Variação \% \\
Administração Pública (Gov) & 1,0014842 & 1,0109335 & 0,9927316 & 0,9872976 & 0,8950725 & 0,9183256 & $-8,30$ \\
Empresas não financeiras (Ent) & 0,7447499 & 0,7714864 & 0,7954893 & 0,7857832 & 0,8143911 & 0,838768 & 12,62 \\
Famílias (HH) & 1,0710808 & 1,0627992 & 1,0683178 & 1,0731213 & 1,0887326 & 1,092299 & 1,98 \\
Resto do mundo (ROW) & 1,0595071 & 1,0448554 & 1,0425975 & 1,0358958 & 1,0887326 & 1,051514 & $-0,75$ \\
Banco Central (BCB) & 1,138771 & 1,1268289 & 1,1128805 & 1,1153726 & 1,0644658 & 1,0762936 & $-5,49$ \\
Empresas financeiras (FF) & 0,9844071 & 0,9830967 & 0,9879834 & 1,0025296 & 1,0486054 & 1,0227998 & 3,90 \\
\hline
\end{tabular}

Fonte: IBGE (2011a). Resultados da pesquisa. Elaboração própria.

O resto do mundo aumentou o PDI-FR e reduziu o PDI-FE, evidenciando o que De Paula e Pires (2017) apontam como mudança na participação do Brasil internacional no fluxo de fundos, mostrando que, nos anos que precedem a crise, o Brasil aumentou os investimentos líquidos no exterior.

As empresas financeiras apresentaram redução no PDI-FR, mas aumentaram o PDI-FE. A redução relevante dos indicadores da capacidade de obtenção de fundos das empresas financeiras, especialmente em 2008, destaca a restrição da liquidez ocorrida com a crise do subprime. Mesmo com as políticas monetárias para prover liquidez aos bancos, a restrição foi visível. A evolução nos indicadores do emprego de fundos das empresas financeiras corrobora o crescimento do volume de crédito ao longo do período, como apontado por Araújo e Gentil (2011). Segundo Freitas (2009), a crise do subprime causou aumento na aversão ao risco e "empoçamento" de liquidez nos bancos privados; logo, credita-se o aumento no PDI-FE específico do ano de 2008 à concessão de crédito pelos bancos públicos, relatado por Slivnik e Feil (2018).

A Figura 4 apresenta a evolução das posições relativas dos setores institucionais (PDI-FR e PDI-FE) durante o período de 2010 a 2015. A Tabela 4 resume as estatísticas descritivas dos PDIs para o período de 2010 a 2015.

As variações que mais chamam a atenção na estrutura de fluxo de fundos no Brasil entre 2010 e 2015 referem-se ao setor externo e às empresas não financeiras. Quanto ao setor externo a variação observada é um indício da consolidação no Brasil como um credor líquido no fluxo de fundos internacional. Destaca-se o crescimento de $41 \%$ no PDI-FR do resto do mundo, revelando que grande parte da poupança doméstica está sendo alocada ao exterior.

As empresas não financeiras continuam a trajetória em que se encontravam antes da crise, apontando para restrição de fontes de financiamento (redução do PDI-FR) e, ao contrário do observado no período precedente à crise, apresentam redução no PDI-FE, o que corrobora as informações de Oreiro (2017) sobre a constante redução na rentabilidade das empresas brasileiras. No período anterior elas estavam investindo suas poupanças em ativos financeiros; no período atual elas não estão formando poupança. 
Tabela 4 - Estatísticas descritivas da evolução do PDI-FR e PDI-FE - Brasil 2004 a 2009

\begin{tabular}{lccccccc}
\hline PDI-FR & 2010 & 2011 & 2012 & 2013 & 2014 & 2015 & Variação \% \\
Administração Pública (Gov) & 1,28 & 1,26 & 1,24 & 1,22 & 1,22 & 1,20 & $-6,95$ \\
Empresas não financeiras (Ent) & 1,24 & 1,23 & 1,22 & 1,21 & 1,22 & 1,20 & $-3,94$ \\
Famílias (HH) & 0,54 & 0,58 & 0,59 & 0,62 & 0,64 & 0,56 & 2,31 \\
Resto do mundo (ROW) & 0,59 & 0,63 & 0,66 & 0,70 & 0,67 & 0,83 & 41,17 \\
Banco Central (BCB) & 1,14 & 1,13 & 1,12 & 1,09 & 1,09 & 1,07 & $-5,74$ \\
Empresas financeiras (FF) & 1,20 & 1,18 & 1,17 & 1,16 & 1,16 & 1,15 & $-4,38$ \\
\hline PDI-FE & 2010 & 2011 & 2012 & 2013 & 2014 & 2015 & Variação \% \\
Administração Pública (Gov) & 0,80 & 0,81 & 0,81 & 0,83 & 0,78 & 0,83 & 3,51 \\
Empresas não financeiras (Ent) & 0,80 & 0,78 & 0,79 & 0,80 & 0,80 & 0,76 & $-4,82$ \\
Famílias (HH) & 1,15 & 1,15 & 1,15 & 1,15 & 1,16 & 1,15 & $-0,59$ \\
Resto do mundo (ROW) & 1,11 & 1,11 & 1,10 & 1,10 & 1,09 & 1,09 & $-1,58$ \\
Banco Central (BCB) & 1,08 & 1,08 & 1,08 & 1,06 & 1,06 & 1,09 & 1,53 \\
Empresas financeiras (FF) & 1,06 & 1,07 & 1,07 & 1,07 & 1,11 & 1,08 & 1,71 \\
\hline
\end{tabular}

Fonte: OCDE (2009-2015). Resultados da pesquisa. Elaboração própria.

Além dessas observações que chamam muito a atenção, dado que são elevadas em comparação às variações verificadas nos demais setores institucionais, outras constatações também merecem ser relatadas, como a redução contínua na capacidade de obtenção de fundos da administração pública e do $\mathrm{BCB}$, o que evidencia a redução no "espaço de política" para a adoção de políticas monetárias e fiscais, destacado por De Paula e Pires (2017), em razão da aceleração inflacionária, desvalorização cambial e deterioração fiscal (destaca-se que no ano de 2014 também houve redução do PDI-FE da administração pública, corroborando a redução no "espaço de política").

Figura 4 - Gráfico da posição econômica dos setores institucionais no fluxo de fundos, Brasil (2004-2009)

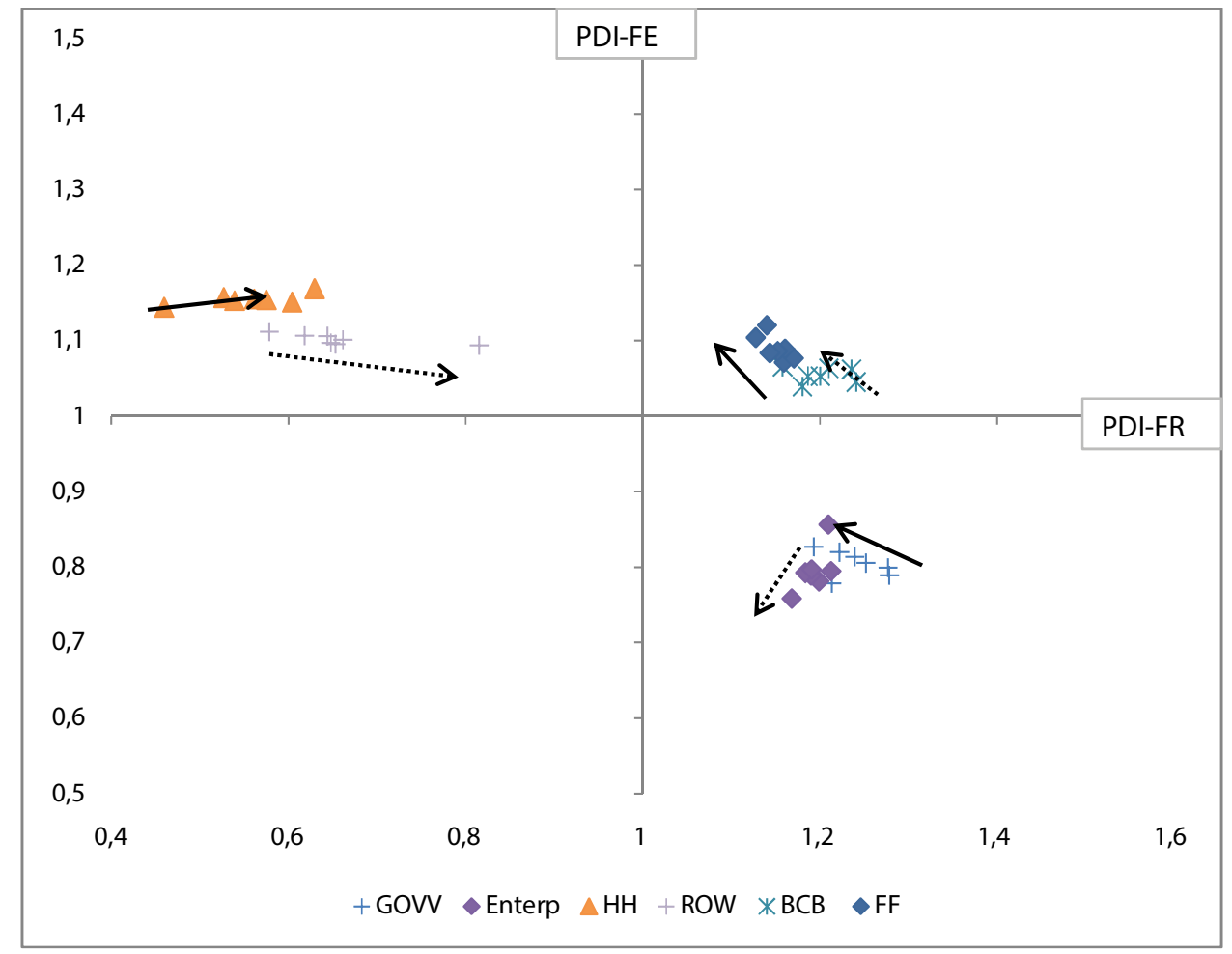

Fonte: OCDE (2009-2015). Resultados da pesquisa. Elaboração própria. 
As condições de restrição financeiras afetaram inclusive as famílias, que, apesar de terem aumentado o PDI-FR, foram muito inferiores ao observado no período precedente à crise (aumento de 2,31 no PDI-FR ante ao aumento de $12,54 \%$ no período anterior). Em relação às famílias, é ainda mais importante destacar que elas tiveram o PDI-FE reduzido no período de 2010 a 2015. Houve diminuição em suas poupanças, mas continuaram sendo um setor estruturalmente poupador, ao contrário do que aconteceu em outros países em que as famílias passaram de um setor poupador (credor líquido) para investidor (devedor líquido). Como destacado Palumbo e Parker (2009), há uma relevante redução nesta capacidade de formação de poupança, o que é um indício de vulnerabilidade, pois, caso essa tendência se mantenha, as fontes de fundos no país serão ainda mais restringidas.

Em suma, os indicadores do poder de dispersão no período subsequente à crise apontam para mudanças estruturais críticas: o setor poupador (famílias) reduzindo sua capacidade de poupança, o setor investidor (empresas não financeiras) reduzindo sua capacidade de investimento e a administração pública, $\mathrm{o} B C B$, e as empresas financeiras, que poderiam amenizar essa configuração desequilibrada, apresentam uma situação de restrição financeira.

\section{CONSIDERAÇÕES FINAIS}

Este trabalho buscou compreender as origens dos "defaults" econômicos no Brasil ocorridos nos anos de 2009, 2015 e 2016, utilizando a análise de fluxo de fundos (FOF) para verificar se eles foram causados por elementos da economia real ou por transações puramente financeiras, e também tem o propósito de discutir os fatores relacionados às questões que fossem constatadas.

Durante o período analisado, desequilíbrios no FOF da economia brasileira foram observados por meio da elevação do indicador de dispersão da discrepância (DDI) nos anos de reversão do crescimento econômico (2008 e 2014). Essa observação demonstra a importância em se acompanhar os indicadores de fluxo de fundos, pois os aumentos na dispersão da discrepância precedem os períodos de "defaults" econômicos no Brasil: em 2008 há um grande aumento na discrepância entre ativos e passivos e, no ano seguinte, 2009, há redução no volume de produção; em 2014 há um aumento na dispersão da discrepância e, nos anos seguintes, 2015 e 2016, há reduções consecutivas no volume de produção.

A decomposição estrutural (SPD) mostrou que as variações na economia real causaram a maior parte das variações que ocorreram no DDI ao longo dos anos, embora o aumento da discrepância em 2008 tenha obtido uma contribuição maior do mercado financeiro, indicando que as alterações de portfólio financeiro foram as principais causas do default de 2009, evidência da proposição de Freitas (2009) quanto ao "empoçamento" de liquidez. Já os "defaults" dos anos de 2015 e 2016 foram causados principalmente por variações na oferta e demanda da economia real. Essas constatações revelam que o "default" de 2009 e os "defaults" dos anos de 2015 e 2016 têm características bem-distintas, mas guardam uma relação em comum: a dificuldade da economia brasileira em manter um nível elevado de crescimento econômico a longo prazo está diretamente ligada ao setor produtivo, reforçando a proposição de Oreiro (2017), quando a baixa taxa de retorno do capital elimina a disposição ao investimento. 
Os indicadores do poder de dispersão (PDI) reforçaram as evidências anteriores e permitiram detalhar um pouco mais a informação. Os setores institucionais ocuparam posições estruturais específicas, mas houve movimentações preocupantes nestas. O impacto da crise do subprime foi refletido pela redução drástica na capacidade de obtenção de fundos do governo, das empresas financeiras, do BCB e das empresas não financeiras no ano de 2008. No ano seguinte as posições foram retomadas. As empresas financeiras fortaleceram sua posição como intermediárias financeiras, e o BCB facilitou esse desenvolvimento ao incentivar políticas creditícias via bancos públicos, aumentando, em 2009, o fluxo de fundos ao setor produtivo.

No período de 2010 a 2015 visualizou-se que as empresas não financeiras reduziram a capacidade de obtenção e de emprego de fundos, o que demonstra restrição financeira e corrosão dos investimentos produtivos, reafirmando a proposição de Oreiro (2017) de que as empresas produtivas vêm reduzindo receita e margens de lucro.

Outra preocupação relevante foi revelada pela observação de que a administração pública reduziu sua capacidade de levantar fundos, refletindo a perda do "espaço fiscal" apontado por De Paula e Pires (2017).

As famílias e o setor externo revelaram aumento na capacidade de obtenção de fundos ao longo de todo o período (2004 a 2015), evidenciando o crescimento da oferta de crédito à pessoa física (ARAÚJO; GENTIL, 2011) e a inversão no papel do Brasil no fluxo internacional de capitais (DE PAULA; PIRES, 2017). Os indicadores, entretanto, mostraram vulnerabilidades, mostrando que o setor externo vem recebendo parcelas muito significativas da poupança interna brasileira e as famílias vêm reduzindo sua capacidade de poupança.

Com as observações destaca-se que a questão estrutural, causa dos defaults recentes, precisa ser resolvida: é necessário reduzir o custo das empresas, em especial o custo do trabalho, de forma a atingir todos os setores, não somente os exportadores, e tomar medidas que permitam flexibilizar as Leis trabalhistas para todos os setores, não somente para os exportadores (evitando que o incentivo "vaze" para o exterior), para que as empresas possam reduzir seu custo total e aumentar sua rentabilidade. É necessário, todavia, que as políticas monetárias sejam coordenadas com as medidas fiscais: é preciso frear o envio de poupança ao exterior e manter a taxa Selic baixa para que o aumento da rentabilidade das empresas retorne para o setor produtivo. Com o aumento da produção, haverá aumento do emprego, que será refletido na renda das famílias, incentivando o consumo doméstico (gerando crescimento econômico) e restaurando suas poupanças. Consequentemente, a taxa de retorno do capital se elevará e, com a taxa Selic baixa, o capital será alocado ao setor produtivo e a economia brasileira começará a caminhar para um crescimento de longo prazo.

Dentre as limitações do trabalho destacam-se a quebra estrutural da base de dados, a defasagem temporal em razão do atraso na publicação dos dados, a disponibilidade somente de dados anuais e a utilização de indicadores de FOF relativos.

Posto que os resultados da análise de FOF representam uma forma alternativa de evidenciar os papéis estruturais que os setores institucionais desempenham na economia, acompanhar a evolução deles é uma forma de monitorar a estabilidade econômica. Destaca-se a necessidade da disponibilização contínua de dados atualizados dos ba- 
lanços patrimoniais financeiros nacionais, com maior periodicidade, por exemplo dados trimestrais, o que permitiria monitorar de forma constante, em tempo real, a evolução do fluxo de fundos, propiciando aos formuladores de políticas econômicas o acompanhamento dos riscos e das vulnerabilidades expressas nos índices de FOF.

Para trabalhos futuros na área sugere-se a atualização das análises ora realizadas à medida que novos dados forem divulgados, a análise de outros indicadores de FOF, como a sensibilidade de dispersão e o valor total das transações financeiras (em valores absolutos) e a desagregação de instituições financeiras em seus diversos subgrupos, como bancos, cooperativas, fundos de pensão e seguradoras.

\section{REFERÊNCIAS}

ARAÚJO, V. L de; GENTIL, D. L. Avanços, recuos, acertos e erros: uma análise da resposta da política econômica à crise financeira internacional. Instituto de Pesquisas Econômicas. Working Paper, n. 1.602. Rio de Janeiro, mar. 2011.

COHEN, J. Copeland's moneyflows after twenty-five years: a survey. J Econ Lit., n. 10, p. 1-25, March, 1972. COPELAND, M. A. Social Accounting for Money-flows. The Accounting Review, v. 24, p. 254-64, 1952.

DE BONIS, R.; POZZOLO, A. F. The financial systems of industrial countries. Evidence from financial accounts. Berlin Heidelberg: Springer-Verlag, 2012.

DE PAULA, L. F.; PIRES, M. Crise e perspectivas para a economia brasileira. Estudos Avançados, n. 31, v. 89, 2017.

DEMONSTRAÇÕES FINANCEIRAS. Banco Central do Brasil. Diretoria de Administração. Departamento de Contabilidade e Execução Financeira. Brasília, 31 dez. 2004-2015. Disponível em: http://www.bcb.gov.br. Acesso em: 29 out. 2017.

FEIJÓ, C. A.; RAMOS, R. L. O. Contabilidade social. Referência atualizada das contas nacionais do Brasil. 4. ed. Rio de Janeiro: Elsevier Editora, 2013.

FREITAS, M. C. P de. Os efeitos da crise global no Brasil: aversão ao risco e preferência pela liquidez no mercado de crédito. Estudos Avançados, n. 23, v. 66, 2009.

HICKS, J. R. The social framework. Oxford: Clarendon, 1942.

IBGE. Instituto Brasileiro de Geografia e Estatística. Sistema de Contas Nacionais. Conta de Patrimônio Financeiro: Brasil 2005-2009. Rio de Janeiro: IBGE, 2011a. Disponível em: http://ibge.gov.br. Acesso em: 5 jan. 2018.

IBGE. Instituto Brasileiro de Geografia e Estatística. Sistema de Contas Nacionais. Nota metodológica n. 8. Rio de Janeiro: IBGE, 2011b. Disponível em: http://ibge.gov.br. Acesso em: 5 jan. 2018.

IBGE. Instituto Brasileiro de Geografia e Estatística. Sistema de Contas Nacionais. Série histórica do Produto Interno Bruto. Rio de Janeiro: IBGE, 2018. Disponível em: http://ibge.gov.br. Acesso em: 20 jan. 2018.

KLEIN, L. R. Lectures in Econometrics. Amsterdam: North Holland, 1983. 233 p.

LEONTIEF, W. W. Quantitative Input and Output Relations in the Economic System of the United States. Review of Economics and Statistics, n. 18, p. 105-125, 1936.

MILLER, R. E.; BLAIR, P. D. Input-Output Analysis: foundations and extensions. 2. ed. New York: Cambridge University Press, 2009.

MITCHELL, W. C. The flow of payments. A preliminary survey of concepts and data. A memorandum, New York: National Bureau of Economic Research, 1944.

OCDE. Organização para a Cooperação e o Desenvolvimento Econômico. 720. Financial account. Non-consolidated. SNA (2008). Paris: OECD, 2009-2015. Disponível em: https://www.oecd-ilibrary.org/economics/ data/financial-balance-sheets/non-consolidated-stocks_data-00025-en. Acesso em: 10 jan. 2018.

OREIRO, J. L. A grande recessão brasileira: diagnóstico e uma agenda de política econômica. Estudos Avançados, n. 31, v. 89, 2017.

PALUMBO, M. G.; PARKER, J. A. The integrated financial and real system of national accounts for the Unites States: does it presage the financial crisis? American Economic Review Papers and Proceedings, $\mathrm{v}$. 99, 2, p. 80-86, 2009.

SLIVNIK, A.; FEIL, F. Caixa, BB e BNDES - notas sobre sua evolução patrimonial recente. Economia e Sociedade, Campinas; Unicam, IE, v. 29, n. 1 (68), p. 195-235, jan./abr. 2020. 
STONE, J. R. N. The Social Accounts from Consumers Point of View. Review of Income and Wealth, v. 12, p. 1-33, 1966.

TAYLOR, S. P. From moneyflows accounts to flow-of-funds accounts. In: DAWSON, J. C. (ed.). Flow-of-funds analysis. A handbook for practitioners. New York; London; Armonk: Sharpe, 1991.

TSUJIMURA, K.; MIZOSHITA, M. Asset-Liability-Matrix Analysis Derived from the Flow-of-Funds Accounts: The Bank of Japan's Quantitative Monetary Policy Examined. Economic Systems Research, v. 15, n. 1, p. 51-67, 2003.

TSUJIMURA, K.; TSUJIMURA, M. A flow of funds analysis of the US quantitative easing. Economic System Research, v. 30, n. 2, p. 137-177, 2018. 